\title{
Clopidogrel and Proton Pump Inhibitors: A New Drug Interaction?
}

\author{
Doson Chua, Jennifer Bolt, Angela Lo, and Anita Lo
}

\section{INTRODUCTION}

O lopidogrel is a thienopyridine platelet antagonist that irreversibly inhibits the binding of adenosine diphosphate to platelet receptors, ultimately leading to inhibition of platelet aggregation. ${ }^{1}$ Clopidogel is a prodrug requiring hepatic bioactivation via cytochrome P450 isozymes (CYP2C19, CYP3A4, CYP3A5) to its pharmacologically active form. Inhibition of cytochrome P450 may interfere with metabolic activation of clopidogrel, reducing its antiplatelet activity and potentially increasing the risk of thrombosis. More recently, the cytochrome P450 2C19 pathway has been identified as the key pathway in clopidogrel bioactivation. ${ }^{2}$

Medications and, more recently, genetic mutations have been shown to affect the activity of the cytochrome P450 2C19 pathway. ${ }^{3}$ Proton pump inhibitors (PPIs), commonly used for prophylaxis and treatment of gastrointestinal bleeding, have been shown to inhibit the cytochrome P450 2C19 pathway to various degrees. ${ }^{4}$ Thus, it is biologically plausible that use of a PPI could impair the metabolic activation of clopidogrel through inhibition of this pathway.

Recent clinical studies have illustrated the potential metabolic interaction between PPIs and clopidogrel, which could result in inhibition of the antiplatelet activity of clopidogrel. The clinical significance of these studies is reviewed below.

\section{METHODS}

PubMed and MEDLINE were searched for the period January 1990 to July 2009 using the terms "clopidogrel", "thienopyridine", "proton pump inhibitor", "drug interaction", "lansoprazole", "omeprazole", "pantoprazole", "esomeprazole", and "rabeprazole". Review articles, letters, commentaries, and unpublished abstracts were excluded.

\section{RESULTS}

Laboratory studies have demonstrated that PPI interferes with the antiplatelet activity of clopidogrel, because of inhibition of cytochrome P450 2C19-mediated activation of clopidogrel (Table 1). One of the first studies investigating this phenomenon involved 124 patients taking clopidogrel, who were randomly assigned to receive omeprazole or placebo. ${ }^{5}$ The platelet reactivity index (PRI), a measure of platelet activity for which higher values have been associated with worse adverse cardiac outcomes, was higher in the omeprazole group than the placebo group. 5 In a prospective cross-over study, Small and others ${ }^{6}$ randomly assigned patients taking clopidogrel to receive lansoprazole or placebo. Relative to placebo, lansoprazole led to a $13 \%$ reduction in the area under the curve and a $29 \%$ reduction in the maximum serum concentration of metabolites of clopidogrel. ${ }^{6}$ This study demonstrated that concurrent use of a PPI with clopidogrel resulted in fewer clopidogrel metabolites, thus illustrating that less bioactivation of the parent drug, clopidogrel, had occurred. In another prospective cohort study, 300 patients receiving clopidogrel were grouped according to concurrent PPI use (specifically pantoprazole or esomeprazole) or no concurrent PPI. ${ }^{7}$ The 2 groups had similar PRI values, which suggested no metabolic drug interaction between clopidogrel and the PPIs. Thus, laboratory studies have provided conflicting results about the potential interaction between clopidogrel and PPIs. However, the results in the study by SillerMatula and others ${ }^{7}$ were explained by the fact that omeprazole is a potent inhibitor of the cytochrome P450 2C19 isozyme, which would lead to inhibition of clopidogrel bioactivation. Other PPIs, such as pantoprazole and esomeprazole, have demonstrated less inhibition of the cytochrome P450 2C19 isozyme, which would mean less interference with clopidogrel bioactivation.?

More recent observational data have illustrated the clinical impact of a potential interaction between clopidogrel and PPI. Juurlink and others ${ }^{8}$ performed a population-based, nested case-control study of patients discharged from hospital after myocardial infarction with a prescription for clopidogrel. Patients who experienced reinfarction during the 90 days after initial discharge (cases) were matched to patients who were at 
Table 1. Studies Investigating Concurrent Use of Clopidogrel and Proton Pump Inhibitors (PPIs)

\begin{tabular}{|c|c|c|c|}
\hline Study & Design & Results & Limitations \\
\hline Gilard et al. ${ }^{5}$ & $\begin{array}{l}\text { Randomized, placebo-controlled trial of } 124 \text { patients } \\
\text { receiving clopidogrel with either omeprazole } 20 \text { mg } \\
\text { daily or placebo for } 7 \text { days }\end{array}$ & $\begin{array}{l}\text { Platelet reactivity index at } \\
7 \text { days: } \\
\text { - Omeprazole group: } 51.4 \% \\
\text { - Placebo group: } 39.8 \% \\
\text { - } p<0.0001\end{array}$ & Laboratory end point \\
\hline Small et al. ${ }^{6}$ & $\begin{array}{l}\text { Prospective, 4-period cross-over study } \\
\text { of } 26 \text { patients } \\
\text { Clopidogrel } 300 \mathrm{mg} \text { load with and without concurrent } \\
\text { lansoprazole } 30 \mathrm{mg} \text { daily* } \\
\text { Patients were crossed over to their respective } \\
\text { treatment arms }\end{array}$ & $\begin{array}{l}\text { Lansoprazole decreased AUC } \\
\text { by } 13 \% \text { and } C_{\max } \text { of } \\
\text { clopidogrel metabolites by } \\
29 \% \text { relative to clopidogrel } \\
\text { alone }\end{array}$ & Laboratory end point \\
\hline Siller-Matula et al. ${ }^{7}$ & $\begin{array}{l}\text { Prospective cohort study of } 300 \text { patients receiving } \\
\text { clopidogrel and undergoing PCI for ACS } \\
\text { Patients grouped as receiving PPI (pantoprazole or } \\
\text { esomeprazole) or not receiving PPI }\end{array}$ & $\begin{array}{l}\text { Platelet reactivity index: } \\
\text { - PPI group: } 51 \% \\
\text { - No PPI group: } 49 \% \\
\text { - } p=0.724\end{array}$ & Laboratory end point \\
\hline Juurlink et al. ${ }^{8}$ & $\begin{array}{l}\text { Population-based nested case-control study of } \\
\text { post-MI patients discharged with a prescription for } \\
\text { clopidogrel (based on Ontario prescription database) } \\
734 \text { of } 13636 \text { patients were readmitted with } \\
\text { recurrent MI within } 90 \text { days } \\
\text { Cases matched to controls on age, PCl, date of } \\
\text { hospital discharge, and predicted short-term mortality } \\
\text { Cases (concurrent PPI), } n=734 \\
\text { Controls (no concurrent PPI), } n=2057\end{array}$ & $\begin{array}{l}\text { No. of patients taking PPI: } \\
\text { - Cases: } 194 / 734 \\
\text { - Controls: } 424 / 2057 \\
\text { - OR } 1.27 \text { (Cl 1.03-1.57) } \\
\text { Subgroup analysis showed no } \\
\text { association between use of } \\
\text { pantoprazole and } \mathrm{H}_{2} \mathrm{RA} \text { and } \\
\text { increased risk of reinfarction }\end{array}$ & $\begin{array}{l}\text { Case-control study } \\
\text { Higher background rates } \\
\text { of other cardiac risk } \\
\text { factors (diabetes, heart } \\
\text { failure) among cases } \\
\text { than among controls }\end{array}$ \\
\hline Ho et al. ${ }^{9}$ & $\begin{array}{l}\text { Retrospective cohort study of } 8205 \text { patients discharged } \\
\text { from hospital after ACS with a prescription for } \\
\text { clopidogrel; use of a PPI at discharge or during } \\
\text { follow-up was captured through a pharmacy database } \\
\text { Clopidogrel and no PPI: } 36.1 \% \text { of sample }(2961 / 8205) \\
\text { Clopidogrel with PPI: } 63.9 \% \text { of sample ( } 5244 / 8205) \\
\text { PPIs used: } 59.7 \% \text { omeprazole }(3132 / 5244), \\
2.9 \% \text { rabeprazole }(151 / 5244) \text {, } \\
0.4 \% \text { lansoprazole }(22 / 5244) \text {, } \\
0.2 \% \text { pantoprazole }(15 / 5244) \text {; } \\
36.7 \% \text { (1924/5244) received more than one PPI }\end{array}$ & $\begin{array}{l}\text { All-cause mortality or } \\
\text { readmission to hospital } \\
\text { for ACS: } \\
\text { - Clopidogrel and no PPI group: } \\
\text { 615/2961 } \\
\text { - Clopidogrel with PPI group: } \\
\text { 1561/5244 } \\
\text { - Adjusted OR 1.25 } \\
\text { (95\% CI 1.11-1.41) }\end{array}$ & $\begin{array}{l}\text { Retrospective cohort study } \\
\text { Higher background rates } \\
\text { of other cardiac risk } \\
\text { : factors (diabetes, heart } \\
\text { failure, renal disease) } \\
\text { in PPI group }\end{array}$ \\
\hline
\end{tabular}

risk but did not experience reinfarction (controls). Patients taking concurrent clopidogrel and PPI therapy had a higher risk of reinfarction than those taking clopidogrel alone (odds ratio [OR] 1.27, 95\% confidence interval [CI] 1.03-1.57). Omeprazole was the main PPI used in this retrospective analysis. Subgroup analysis suggested that pantoprazole and histamine -receptor $^{2}$ antagonists were not associated with the higher risk of reinfarction. In another recent observational study, Ho and others ${ }^{9}$ retrospectively investigated 8205 patients who were discharged from hospital with a prescription for clopidogrel after acute coronary syndrome. Clopidogrel and PPI use were identified through pharmacy databases. Concurrent use of clopidogrel and PPI was associated with a higher rate of death or readmission to hospital for acute coronary syndrome than the use of clopidogrel without concurrent PPI (OR 1.25, 95\% CI 1.11-1.41). In subgroup analysis of the cohort receiving clopidogrel and PPI concurrently, the risk of death or readmission to hospital was increased with use of omeprazole and rabeprazole. Other PPIs were not analyzed, given the small proportion of patients in the concurrent clopidogrel and PPI study cohort who were taking these drugs.

\section{DISCUSSION}

Initial studies illustrating the potential of a drug interaction between clopidogrel and PPI used laboratory end points, mainly related to platelet activity. Although platelet activity has been associated with clinical outcomes such as thrombosis and cardiac events, several measures of platelet activity have been reported in the literature (e.g., optical aggregometry, whole-blood aggregometry, measurement of urinary or serum thromboxane, platelet function assays), with no universally adopted standard. As well, the assays employed to assess platelet reactivity are numerous and vary in sensitivity and specificity. Thus, there is no established laboratory standard for the measurement of platelet reactivity, which makes interpretation of the various studies more difficult. 
Two recent retrospective studies have illustrated the clinical implications of the apparent interaction between clopidogrel and PPI. ${ }^{8,9}$ Because these studies were retrospective, they established only an association and not a causal relationship between concomitant use of clopidogrel and PPI and adverse clinical outcomes. Furthermore, they were subject to the flaws inherent in all retrospective observational studies, namely biases and multiple confounding factors. Both studies established that the concurrent use of clopidogrel and PPI was associated with higher rates of reinfarction and readmission to hospital than use of clopidogrel alone. This phenomenon is thought to be a result of inhibition by PPI of clopidogrel bioactivation by the cytochrome P450 2C19 isozyme. Mechanistically, in vitro interaction between omeprazole and clopidogrel has been demonstrated, 5 an interaction that was confirmed by the 2 recent retrospective studies. Omeprazole is metabolized by the cytochrome P450 2C19 isozyme to a greater extent than other PPIs, which may make this PPI more likely to interfere with clopidogrel bioactivation. Other PPIs (e.g., pantoprazole) are metabolized by different metabolic pathways and demonstrate less inhibition of CYP2C19; use of these PPIs may avoid or limit the potential for an interaction with clopidogrel.

Although omeprazole was the most common PPI used in the 2 recent studies, there are insufficient clinical data to suggest that another PPI (pantoprazole) would be devoid of this affect on clopidogrel. The subgroup analysis of the PPI cohort in the study by Juurlink and others ${ }^{8}$ suggested that pantoprazole lacks this interaction with clopidogrel. The danger with drawing this conclusion is that the main study was a retrospective, nested case-control study; as such, performing subgroup analysis is fraught with potential biases and errors. The study by Ho and others ${ }^{9}$ had insufficient patients taking pantoprazole to allow a subgroup analysis to determine if that PPI lacked the interaction. The suggestion that there is a specific PPI that does not exhibit this drug interaction is based on subgroup analysis of retrospective data and must therefore be interpreted with caution.

The evidence that one PPI might be safer than another for patients also taking clopidogrel is evolving and controversial. An analysis of the Clopidogrel for the Reducation of Events During Observation (CREDO) study illustrated that use of a PPI increased cardiovascular events regardless of whether patients were receiving clopidogrel. ${ }^{10}$ A preliminary presentation on the Medco Outcomes study, the largest study of this topic to date (with 16690 patients), showed that concurrent use of clopidogrel and a PPI led to more cardiovascular events than use of clopidogrel alone. ${ }^{11}$ The increased risk of cardiovascular events was similar among all PPIs studied (omeprazole, esomeprazole, pantoprazole, and lansoprazole), with the highest rate of cardiovascular events occurring among patients taking pantoprazole. Thus, there are conflicting data about whether one particular PPI is safe for use by patients taking clopidogrel.
The US Food and Drug Administration is reviewing the data on interactions between clopidogrel and PPIs, but firm recommendations have yet to be made. ${ }^{12}$ The latest guidelines from the American College of Cardiology and the American College of Gastroenterology recommend that PPIs should be prescribed when there is a clinical indication for them. ${ }^{13}$

\section{CONCLUSIONS}

Evidence is emerging of an association between concurrent use of clopidogrel and PPIs and adverse cardiac outcomes, which supports the mechanistic hypothesis that PPI inhibits the bioactivation of clopidogrel. However, the data are conflicting, and it is not clear if there is one PPI that is safer than the others.

On the basis of the data available, use of PPIs should be avoided by patients who are already taking clopidogrel. Histamine $_{2}$ receptor antagonists should be considered, if appropriate, in lieu of a PPI. If a PPI is absolutely necessary, omeprazole should be avoided, given laboratory and clinical studies that have consistently demonstrated an interaction. Pantoprazole is preferred if a PPI is strongly indicated, based solely on laboratory and mechanistic data. The benefit of spacing the administration of clopidogrel and PPI over time, to minimize the impact of this potential drug interaction, is unclear.

Other review articles that have recently been published on this drug-drug interaction ${ }^{14,15}$ confirm that the literature about this particular interaction is constantly evolving. These review articles reached a similar overall conclusion as did the authors of the current review: that concomitant administration of clopidogrel and PPIs should be avoided because of a purported drug-drug interaction. The reviews differed slightly in their recommendation as to whether one particular PPI is safe for use with clopidogrel, because of differing interpretations of subgroup analyses of the published studies included in the reviews and differing relative emphasis on laboratory and clinical results. Interestingly, more recent evidence from prospective randomized trials suggests no clinically significant drug-drug interaction between clopidogrel and PPIs at all. 16,17 The results of these 2 prospective studies are not covered in the current review, because the current article was already in production at the time these 2 trials were published. The evidence for the drug interaction between clopidogrel and PPIs continues to evolve, and health care professionals must remain alert to further evidence as it arises.

\section{References}

1. Chua D, Ignaszewski A. Clopidogrel in acute coronary syndromes. BMJ 2009;338:b1180.

2. Shuldiner AR, O'Connell JR, Bliden KP, Gandhi A, Ryan K, Horenstein $\mathrm{RB}$, et al. Association of cytochrome P450 2C19 genotype with the antiplatelet effect and clinical efficacy of clopidogrel therapy. JAMA 2009;302(8):849-857.

3. Simon T, Verstuyft C, Mary-Krause M, Quteineh L, Drouet E, Méneveau $\mathrm{N}$, et al.; French Registry of Acute ST-Elevation and Non-ST-Elevation 
Myocardial Infarction (FAST-MI) Investigators. Genetic determinants of response to clopidogrel and cardiovascular events. New Engl J Med 2009;360(4):363-375.

4. Li QX, Andersson TB, Ahlström M, Weidolf L. Comparison of inhibitory effects of the proton pump-inhibiting drugs omeprazole, esomeprazole, lansoprazole, pantoprazole, and rabeprazole on human cytochrome $\mathrm{P} 450$ activities. Drug Metab Dispos 2004;32(8):821-827.

5. Gilard M, Arnaud B, Cornily JC, Le Gal G, Lacut K, Le Calvez G, et al. Influence of omeprazole on the antiplatelet action of clopidogrel associated with aspirin: the randomized, double-blind OCLA (Omeprazole Clopidogrel Aspirin) study. J Am Coll Cardiol 2008;51(3):256-260.

6. Small DS, Farid NA, Payne CD, Weerakkody GJ, Li YG, Brandt JT, et al. Effects of the proton pump inhibitor lansoprazole on the pharmacokinetics and pharmacodynamics of prasugrel and clopidogrel. J Clin Pharmacol 2008;48(4):475-484.

7. Siller-Matula JM, Spiel AO, Lang IM, Kreiner G, Christ G, Jilma B. Effects of pantoprazole and esomeprazole on platelet inhibition by clopidogrel. Am Heart J 2009;157:148e1-5.

8. Juurlink DN, Gomes T, Ko DT, Szmitko PE, Austin PC, Tu JV, et al. A population-based study of the drug interaction between proton pump inhibitors and clopidogrel. CMAJ 2009;180(7):713-718.

9. Ho PM, Maddox TM, Wang L, Fihn SD, Jesse RL, Peterson ED, et al. Risk of adverse outcomes associated with concomitant use of clopidogrel and proton pump inhibitors following acute coronary syndromes. JAMA 2009;301(9):937-944.

10. Dunn SP, Macaulay TE, Brennan DM, Campbell CL, Charnigo RJ, Smyth SS, et al. Baseline proton pump inhibitor use is associated with increased cardiovascular events with and without the use of clopidogrel in the CREDO trial [abstract 3999]. Circulation 2008;118:S_815.

11. Stanek EJ, Aubert RE, Flockhart DA, Kreutz RP, Yao J, Breali JA, et al. A national study of the effect of individual proton pump inhibitors on cardiovascular outcomes in patients treated with clopidogrel following coronary stenting: the Clopidogrel in Medco Outcomes Study [lecture presentation]. In: 32nd Annual Scientific Sessions of Society of Coronary Angiography and Intervention; 2009 May 6; Las Vegas (NV).

12. Early communication about an ongoing safety review of clopidogrel bisulfate (marketed as Plavix). Rockville (MD): Food and Drug Administration; 2009 Jan 26 [cited 2010 Jan 13]. Available from: w w w. f d a g o v/ D r u g s / D r u g S a f e t y / PostmarketDrugSafetyInformationfoPatientsandProviders/ DrugSafetyInformationforHeathcareProfessionals/ucm079520.htm

13. Bhatt DL, Scheiman J, Abraham NS, Antman EM, Chan FK, Furberg CD, et al.; American College of Cardiology Foundation Task Force on Clinical Expert Consensus Documents. ACCF/ACG/AHA 2008 expert consensus document on reducing the gastrointestinal risks of antiplatelet therapy and NSAID use: a report of the American College of Cardiology Foundation Task Force on Clinical Expert Consensus Documents. Circulation 2008;118(18):1894-1909.
14. Norgard NB, Mathews KD, Wall GC. Drug-drug interaction between clopidogrel and the proton pump inhibitors. Ann Pharmacother 2009; 41:1266-1274.

15. Last EJ, Sheehan AH. Review of recent evidence: potential interaction between clopidogrel and proton pump inhibitors. Am J Health Syst Pharm 2009;66(23):2117-2122.

16. O'Donoghue ML, Braunwald E, Antman EM, Murphy SA, Bates ER, Rozenman Y, et al. Pharmacodynamic effect and clinical efficacy of clopidogrel and prasugrel with or without a proton-pump inhibitor: an analysis of two randomised trials. Lancet 2009;374(9694):989-997.

17. Wood S. COGENT: No CV events but significant GI benefits of PPI omeprazole. Montreal (QC): theheart.org; 2009 Sep 24 [cited 2009 Oct 13]. Available from: www.theheart.org/article/1007145.do. Membership required to access content.

Doson Chua, BSc(Pharm), PharmD, BCPS(AQ), is with the Department of Pharmacy, St Paul's Hospital, Vancouver, British Columbia.

Jennifer Bolt, BSC(Pharm), PharmD, is with Kelowna General Hospital, Kelowna, British Columbia.

Angela Lo, BSc(Pharm), MSc, MHA, is with the Vancouver Coastal Health Authority, Providence Health Care, Vancouver, British Columbia.

Anita Lo, BSc(Pharm), PharmD, is with Ridge Meadows Hospital, Maple Ridge, British Columbia.

\section{Address correspondence to:}

Dr Doson Chua

Department of Pharmacy

St Paul's Hospital

1081 Burrard Street

Vancouver BC V6Z 1 Y6

e-mail: dchua@providencehealth.bc.ca 